Revista Iberoamericana. Vol. LXIII, Núms. 178-179, Enero-Junio 1997; 175-184

\title{
CIUDADANÍAS DEL COSTUMBRISMO EN VENEZUELA
}

\author{
POR \\ JAVIER LASARTE VALCÁRCEL \\ Universidad Simón Bolivar, Venezuela
}

\begin{abstract}
Mi periódico [El Museo Venezolano] debía contener (...) varias secciones, siendo la que yo sabía que agradaría más a los lectores, la del Artículo de Costumbres.'
\end{abstract}

"Durante un siglo nuestras letras han oscilado entre el lirismo delirante y etéreo y la más pesada chacota (...). Los 'costumbristas' chapoteaban en el barro...” (Semprum 235). La afirmación la hizo, con el XIX a sus espaldas, el crítico venezolano Jesús Semprum. Y como se ve, al costumbrismo le correspondía allí un papel protagónico en la caricatura. De hecho, de entonces a hoy, en no pocas oportunidades, "costumbrismo" o "costumbrista" ha servido como el más eficaz término usado para descalificar tendencias vinculables al mundo de los nacionalismos literarios. Incluso en años recientes, ocasionalmente, $\mathrm{y}$ a veces con razón, se presenta el género de los artículos, cuadros o relatos costumbristas como "una modalidad que no se caracteriza por sus sobresalientes méritos estilísticos, por su cabal calidad literaria" (Bueno ix); o se desestiman irónicamente sus alcances: "Desde el punto de vista social, la función del costumbrismo fue - por decirlo de alguna manera - mucho más municipal que nacional" (Cornejo Polar La formación 31). Pero aunque sobre el costumbrismo planee razonablemente el fantasma de su minoridad, de su inmediatez e intrascendencia, difícilmente podrá cuestionarse el protagonismo que el género adquirió en la constitución del campo cultural durante la formación de las naciones latinoamericanas o el relieve que tiene para la comprensión de esa época.

El emplazamiento del género costumbrista, dondequiera se halle, no puede desligarse del hecho mismo del tránsito a la modernización; más específicamente: "the costumbrismo was necessarily an ideological manifestation of the transition to modern, burgeois society" (Kirpatrick 31). Es, pues, como su marco comunicacional, la prensa - con cuyo carácter es concomitante en más de un sentido-, uno de los discursos culturales constitutivos de la sociedad moderna. Y si la prensa periódica fue desde ese tiempo expresión alegórica y uno de los motores de la idea moderna de nación (Anderson), el género costumbrista ostentó dentro de ella - al menos hasta la primera década del XX - la condición de espacio estelar, dado el éxito de su recepción y en tanto escenificaba especularmente -y contribuía a instaurar - temas y obsesiones de su comunidad lectora.

\footnotetext{
${ }^{1}$ Bolet Peraza 11.
} 
El advenimiento del género costumbrista en Venezuela, como en el resto de América Latina, difícilmente puede desligarse de hechos históricos centrales, como la instalación de la sociedad postindependentista, la formación de la nueva nación, los pasos iniciales del proyecto modernizador, el nacimiento y expansión de la prensa, o la misma recepción del costumbrismo español. Su póetica general parte de la idea de una literatura "útil y progresiva", articulada a usos y costumbres de una comunidad particular. Su carácter, al menos en sus inicios, tiene que ver, según la postura del articulista, más que con el acopio de esas costumbres sociales, con el moldeamiento de otras nuevas que contribuyeran a diseñar y forjar la figura del ciudadano; o con la crítica de los frutos (casi siempre pervertidos) de la nueva sociedad. En un trabajo reciente, Cornejo Polar definía el costumbrismo como un "nuevo 'pacto de lectura" de "sentimientos y puntos de vista socializados", y describía acertadamente la particular dinámica que suponía ese pacto:

... su intencionalidad supone al menos la posibilidad de convencer el lector de la legitimidad de la propuesta que el texto encarna sin mayores disimulos, todo bajo la presuposición - claro está - de que su objetivo final no es otro que el progreso de la nación. De esta manera, el escritor se autoasume como representante y portavoz de la opinión pública, o de un sector de ella, y al mismo tiempo intenta modelarlay ocasionalmente movilizarla desde una determinada perspectiva y hacia una determinada dirección. Así, al menos dentro de la ficción que recubre todo texto, el costumbrismo aparece incisivamente penetrado por un público al que tanto dice representar cuando desea - especialmenteformar y dirigir (Cornejo Polar "La literatura hispanoamericana" 14).

Acaso también sea posible, a partir de esta descripción de base, pensar el costumbrismo, por un lado, como un género no necesariamente uniforme, que participa en el tiempo de diversas funciones, y que, a lo largo del siglo XIX, interviene en la discusión y produce imágenes sobre las ideas de nación y de pueblo - haciendo la salvedad de que, para la mayoría letrada de ese momento, ambas ideas se recortaban tan sólo a partir del paisaje humano de la ciudadanía; es decir, de la parte ilustrada de esa comunidad; es decir, de ella misma. Y, por otro, como un género al que concurren miradas diversas, decidoras de la particular situación y posición desde la cual sus escritores producen estos cuadros.

\section{BARBARIE Y PACTO NACIONALISTA.}

En el caso venezolano, la crítica ha destacado el estrecho vínculo existente entre el género costumbrista y la constitución de la nueva nación. Así, ha sido sucesivamente presentado como "primera vía (...) hacia lo circundante, en el proceso de nuestras letras, después que Venezuela se hace independiente" (Picón Salas 5); "historia viva de toda una inmensa sociedad en período de formación" (Díaz Seijas 426); o como "espacio para mirarse a través de la palabra, una forma (...) que les permitía al fin [a nuestros noveles republicanos] ejercer su deseo y necesidad de comenzar a conocerse como ente colectivo" (Barrios 18). Asimismo ha resaltado su función crítica (Díaz Seijas, Barrios), sus estrategias y formas básicas — - humor grotesco e hiperbólico, la ironía más o menos sarcástica, el extrañamiento, su constante apelación al lector...- (Barrios), e incluso ha diseñado una plausible periodización del género en tres etapas - que aquí se reducirán a dos, a veces con 
la ocasional señalización de variantes y cambios pertinentes. No obstante, la tendencia general ha consistido en leer los momentos de este género como todos homogéneos, lo que no siempre se ajusta a la realidad de los textos y a la relativamente breve historia del género.

Durante las primeras décadas de su actuación, entre los años treinta y la Guerra Federal, los más conocidos representantes del género tienden a menudo a establecer un balance entre el deseo y la realidad: esto es, transcurridos años o décadas de las luchas emancipadoras, se preguntan por el estado actual de la sociedad postindependentista, por el estado del propio espacio respecto de sus modelos de modernización y, si hay signos visibles de cambio, se preguntan también por si es esa aplicación específica del modelo la que más conviene a la futura nación moderna. A la hora de hacer el bosquejo del espacio nacional y sus tipos humanos -concentrados casi siempre en la ciudad: el espacio futuro a diseñar-, la mayoría de estos primeros costumbristas, confirman la necesidad de "construir a partir de cero una cultura, romper con la tradición colonial y fundar en el 'desierto"' (Sarlo xiv). Esta imagen del espacio nacional como desierto cultural, como espacio bárbaro, presente en textos de Juan Manuel Cagigal, Rafael María Baralt o Luis Delgado Correa, podría asimilarse con relativa facilidad a la que coetáneamente hicieran célebre en sus textos los civilizadoristas rioplatenses: Echeverría, Alberdi, Sarmiento. La principal motivación de estos costumbristas será la representación del "choque del hombre culto con un medio que encuentra todavía primitivo y desorganizado" (Picón Salas 6); por lo que "... su enfoque, condicionado por una episteme racional (...), tiende a cerrarse en una suerte de desdén aristocratizante hacia las manifestaciones callejeras" (Barrios 99-100).

En efecto, esta línea del costumbrismo inicial moldea en negativo, construye la idea de un vacío cultural. Así, en uno de los textos fundacionales del género costumbrista en Venezuela, "Contratiempos de un viajero" (1839) de Cagigal, pueblo y país se dibujan sólo desde la carencia y el sarcasmo. Pueblo es ése que "contempla impávido y sereno la destrucción de su obra" (Antología 15), el "activo" e "industrioso" dado a la conservación de las ruinas (17), compuesto de Carones de "alma acorchada" y bellas caraqueñas "armadas de descomunales jeringas" (24), regulado por normas absurdas y entregado al salvajismo del carnaval; el país, ese espacio donde hasta un barómetro puede quedar sometido a "la influencia perturbatriz de [la] atmósfera local" (19), un espacio, en fin, "infernal" (18), que deja sus marcas - las heridas- en el cuerpo extraño del viajero. La máscara del viajero sanciona con su ironía sarcástica la barbarie y expresa la nostalgia del que se duele porque "a [esas] horas estaría holgándo[se] en los Elíseos Campos" (20). Es la nostalgia de otro espacio: la ausencia del modelo civilizatorio en la realidad nacional; en otras palabras, la ausencia del ciudadano.

La imagen del espacio bárbaro, físico y humano, la idea del desierto cultural, se refuerza si el lector revisa otros autores costumbristas de este tenor. Así, Rafael María Baralt —quien acude al género por solicitud de Cagigal—, en "Lo que es un periódico" (1839) — como para incomodar la idea de "pacto"- esboza un retrato del "respetable público" [lector], es decir, del candidato a ciudadano, caracterizándolo como antojadizo, tornadizo, débil, traicionero, parasitario, superficial, prejuiciado y falso, irrespetuoso de los grandes principios liberales civilizatorios, sin ciencia, arte ni industria. En otro texto posterior, "Los escritores y el vulgo" (1839), Baralt confirma y concentra su distancia jerárquica respecto del otro, al representarlo como ave de rapiña, antagonista cruel y desalmado: "necios 
terribles, necios respetables" (Antología 66), que copan el espacio social y asfixian la voz distinta del autor, extraño en tierra propia.

Por su parte, Luis Delgado Correa, desde una perspectiva acaso más conservadora, ratifica también la negación del presente postindependentista. En "Los gigantes y los diablos" Delgado Correa repite el tema del extranjero - "Desgraciado europeo" (Antología 69) - en el carnaval, con el añadido de la sugerencia según la cual la bárbara festividad es una cabal alegoría del "progreso y civilidad" que ha(n) alcanzado la(s) política(s) de la nación. Pero en otro texto suyo, "Un día festivo en Caracas"; Correa Delgado introduce una variante, que por lo demás no es ajena al texto de Cagigal: la idea del presente como decadencia ante un pasado glorioso, el de los años y hombres fundadores de la emancipación, únicos dignos para este tipo de escritores de integrar la galería de la civilización americana (espacio museístico que fuese fijado desde los años veinte por la "Alocución a la poesía" de Bello). Allí, un paseante, versión criollizada del voyeur, registra, en un paneo selectivo, la ciudad en fiesta. Las muestras seleccionadas, balance y sanción del paisaje urbano, confirman por acumulación de imágenes la idea de que los cambios sociales han optado por seguir los pasos de la degradación. Para empezar el narrador admite que al menos en un día de fiesta la plaza muestra una apariencia más higiénica que el diario "grotesco" de la "muchedumbre (...) sucia y desaliñada", de los "ranchos portátiles" que hacen de ella un "albañal inmundo"(Antología 72). Pero las escenas que siguen a esta salvedad no permiten que el narrador fije algo más que la mirada en los espacios públicos de las calles de Caracas, pues en ningún espacio puede reconocerse e insertarse. Así, en la iglesia campea el irrespeto a los actos religiosos; y en la plaza, la "apatía", la "indiferencia", el "adormecimiento del lujo y las pasiones afeminantes". Las calles han sido ganadas por sus modelos, los nuevos ricos, "bípedos racionales" convertidos en "cuadrúpedos" (77) amantes del oro. La gallera rivaliza victoriosamente con el Tedeum, y la corrida de toros con las luchas del pasado contra la tiranía. El saldo: la huida ante el cambalachesco fin de mundo, el lamento de autor __ ¡O tempora, o mores!” (80), el refugio en el espacio privado, el mirar hacia adentro: la cama y el sueño. La diferencia de postura de este texto costumbrista acaso resida en la índole del baremo enjuiciador: la moral, la fe, el heroísmo del pasado, y no París o la cartilla del ciudadano liberal; la coincidencia, en el menosprecio "aristocratizante" de la nueva sociedad, el diseño de la imagen decadente y grotesca (más que bárbara en este caso) de su comunidad.

Con Fermín Toro y, sobre todo, Daniel Mendoza, se halla otra línea, coetánea y divergente respecto de la fundada por Cagigal, próxima a la que, en otro tipo de discursos, establecieran civilistas venezolanos como Bello, Rodríguez o el propio Toro: la tendencia que se ocupa de señalar los efectos perversos y grotescos de la nueva cultura de la modernización, al asimilarse sin pasar por el tamiz de la propia realidad. "Toda transplantación es peligrosa, porque hay que vencer las dificultades de un terreno extraño, y es después de un detenido estudio sobre la naturaleza de éste (...) que se pueden sentir los buenos resultados de una perfecta localización" (Antología 109), dirá Daniel Mendoza en "Los muchachos a la moda" (1845). A esa voluntad asimiladora crítica obecede tanto la caracterización del caricaturesco personaje de "Un romántico" (1842), de Toro, patético e histérico ejemplo de la nueva sociedad; como, en el propio "Los muchachos a la moda", el personaje de Petito, el "non plus ultra" de los bardos y poléticos a sus catorce años; o la 
Pepita de "Gran sarao o las niñas a la moda" (1845), también de Mendoza, la frívola niña que sintomáticamente oculta la magrura de su cuerpo con la trampa que facilitan "las mercancías del Sena" (Antología 141), que llena su "cabeza de arias, de cavatinas, de dibujos, de un mal francés" (Antología 142) y sólo se ocupa de dormir y leer las noticias sobre modas. Obviamente aquí la discusión de fondo sigue siendo, como en Cagigal, la de los grandes modelos, la disyuntiva entre civilización y barbarie: el gran emplazamiento discursivo de este primer costumbrismo. Pero la opcion es otra.

Es el camino que, desde una otra posición conducirá, al cierre de esta etapa inicial del costumbrismo, al opuesto de Cagigal: "Un llanero en la capital" y "Palmarote en Apure", los textos "clásicos" de Daniel Mendoza, suerte de díptico en el que la posicion nacionalista se despliega con mayor complejidad. La escena se establece sobre la confrontación de lo moderno y lo tradicional, la ciudad y el campo; o, en otras palabras, de la civilización y lo que era tenido por barbarie. Los personajes de estos textos costumbristas -el llanero y el capitalino, que no dejan de ser en última instancia emblemas-encarnan alegóricamente los grandes términos en pugna. La inversión ideológica dentro del mismo sistema discursivo ocurre con la proposicion de un pacto mestizador como símbolo de la nueva nacionalidad. El mismo se expresa en el cambio de conciencia que ocurre, de uno a otro texto, en el narrador capitalino - semejante en su autopresentación inicial a un "pepito" extranjerizante-; cambio refrendado por la visita que hace en el segundo texto a la casa de Palmarote en el llano. Y se manifiesta asimismo tanto en el espacio concedido a la voz del emblema de lo popular como en el reconocimiento autorial de que esa voz ejerce un saber legítimo —el predominio modal del diálogo contrapuntístico en "Un llanero en la capital" es en este sentido más que significativo. El pacto de amistad se expande a otros ámbitos y supone el pacto de la ciudad y el campo, del ciudadano y el llanero, de (aparente) civilización y (aparente) barbarie, de modernización y tradición, al punto de proponer, en las primeras páginas de "Palmarote en Apure", la ciudad rural como concreción simbólica y utópica de la nueva nación deseada (Antología 148-9).

\section{MODERNIZACIÓN, TRADICIÓN Y CIUDADANÍA}

Las últimas décadas del XIX y la primera del XX, las correspondientes al modernismo literario, suponen la eclosión o el desarrollo de una multiplicidad de géneros que, en cierta forma, desde una perspectiva actual, podrían hacer pensar en la decadencia del costumbrismo, aun más cuando nuevas formas próximas como la tradición o la crónica parecen disputarle su espacio. Acaso ese efecto es lo que puede llevar a algún crítico a afirmar que la necesidad de "aspiraciones y estructuras nuevas" llevó a "sustituir al costumbrismo que después de medio siglo, había perdido vigencia por desgaste y carencia de posibilidades" (Núñez ix$\mathrm{x}$ ). No obstante, ese proceso no se verifica en todos los casos, y más que en la disolución del género — cosa que no ocurrirá efectivamente sino poco después, en cuanto se disuelva el patrón de literatura sobre el que se fundó el genero- habría que pensar en una refuncionalización del costumbrismo en convivencia con las nuevas fórmulas - leyendas históricas, tradiciones, crónicas, narraciones que incorporan registros costumbristas pero con funciones más cercanas a las del etnólogo o el folklorista. 
Para el caso venezolano la crítica ha reseñado de algun modo este viraje del costumbrismo. Alba Lía Barrios señala con perspicacia que en las últimas promociones de costumbristas se transforman "sustancialmente mirada, tono e incluso la interpretación ideológica" (Barrios 20). Picón Salas apunta que encaminándose hacia el fin del siglo el costumbrismo busca interpretar "esta como vida subterránea y burlona, la de los sobrenombres y la anécdota diaria que siempre coexistió en Venezuela junto a la grave vida oficial" (Picón Salas 7), y añade que en el "Versalles del guzmancismo" "es otra fauna humana la que inspira a los costumbristas' (Picón Salas 6). Y Díaz Seijas advierte que, a partir de Bolet Peraza, el costumbrismo se abre al dibujo de las "pintorescas(s) psicología(s)" de tipos sociales (Díaz Seijas 429), registrando en representantes posteriores —para él, de la decadencia del género (7) - una serie de rasgos, por demás llamativos a nuestros efectos: el uso de un "lenguaje mordaz, ... lindante con la chabacanería", la exhibición de las "intimidades de la clase media", discursos "pornográfico(s) en cierto grado" ( $¿$ ?) (Díaz Seijas 433) en Rafael Bolívar; la "confesa nostalgia por el derrumbe de la tradición" (Id: 434) en Méndez y Mendoza-; o el memorialismo de Miguel Mármol, sus "pasajes, llenos de travesuras y de chispeante realidad venezolana" (Díaz Seijas 434). A lo que acaso podría añadirse la crítica esporádica del poder autoritario —en "El señor maestro" de Bolet Peraza - de la farsa del sistema educativo —en "Los exámenes" de Rafael Bolívar-o, en muchos de ellos, del mundo de las convenciones burguesas. Rasgos todos que apuntan a la instauración de otro tipo de sujeto autorial.

Estos señalamientos podrían ser reagrupados por dos hechos que redimensionan el alcance de esas novedades: de una parte, la aceptación de la modernización como una realidad irrefrenable; y, de otra, la desmembración del mundo concreto, la constitución de campos específicos del saber y del hacer con el consiguiente cambio de situación y función del escritor. En ese marco se asienta, por parte de los autores costumbristas, el abandono o reajuste de la discusión del gran modelo - civilización o barbarie-y el surgimiento de otras funciones: la concentración escritural en tipos sociales, sicológicos o morales, el despliegue de un humor menos "macropolitizado", o la crítica autónoma, sin que ello quiera decir que se abandonen por completo las funciones que se ejercieran en los desempeños iniciales del género.

Si hubiera que definir algunas de las nuevas funciones e imágenes que expresan el cambio, podría establecerse una tríada de proposiciones que a veces corren entrelazadas: 1) la constitución de una tradición, en tanto el cuadro o artículo de costumbres se escribe como el registro nostálgico y compensatorio - “inventándolo, si era necesario" (Oviedo ix)— de lo que irremisiblemente ha de desaparecer y como un mecanismo para afrontar desencantada o positivamente los nuevos tiempos (con lo que la función del género es concomitante con el auge de tradiciones y leyendas o la práctica historiográfica, por ejemplo). 2) El moldeamiento moral del ciudadano bajo la forma de la loa o la diatriba, para lo cual ya no se recurre a gruesas descalificaciones del todo social ni a emblemas simbólicos de la nación humana, ni a conductas político-ideológicas, sino a tipos morales o individuos de varia extracción, reveladores de diversas culturas de conducta social; se trata de personajes que se acercan más a la "persona" que a la entelequia - la barbarie, lo rural ...-: los ciudadanos como pequeños héroes o antihéroes. Y 3) la frecuente asimilación del otro social, incluso ocasionalmente de los hijos de la barbarie, de su voz y su actitud, como modelos o espacios 
posibles de una nación ahora concebida en términos más heteróclitos y heterogéneos, y, por tanto, más inasibles, menos identificables, como no sea en términos del individuo ciudadano como producto simbólico de la futura nación burguesa.

Así, por ejemplo, un texto costumbrista como "El Mercado", de Nicanor Bolet Peraza, pone en funcionamiento al menos dos de estas líneas y escenifica el nuevo marco desde el que se escribe. La escena se abre con la testificación autorial del acto de la demolición de la vieja Plaza de Armas y el Mercado, que dará paso a la construcción de la moderna Plaza Bolívar. En el texto los golpes de las "piquetas" de los "cien obreros" serán contrapesados por las palabras del costumbrista, del mismo modo que la modernización propiciará la fabulación de su tradición. La nostalgia por el otro espacio -el civilizatorio, parisinode Cagigal se trocará aquí en una nostalgia por otro tiempo. No obstante, no se cuestionará la demolición, pues lo viejo en la realidad "no era decoroso", ganado como estaba por grasas varias y "pléyades de moscardones verdes" (Antología 212). En compensación por la pérdida cultural - ya que no histórica - la imaginación del escritor costumbrista de la modernización clamará por un mestizaje de tiempos - tradición y modernidad- que él mismo reconocerá como retórico e inútil en la realidad histórica:

¿Quién ha dicho que no hubiera podido aprovecharse la vieja estructura, combinándola con las obras nuevas de embellecimiento que el progreso de nuestra culta capital estaba reclamando? Vamos, la cosa no tiene ya remedio. Lo bonito ha sustituido a lo histórico y solemne (Antología 212).

La posibilidad de la alianza de tiempos se fundará, sin mayor conflicto, amablemente, en la escritura. La escritura del género costumbrista se constituirá ahora a partir de su capacidad para transfigurar espacio físico "indecoroso", y convertirlo en objeto cultural, en tradición. Por esa gracia de la escritura el Mercado - viejo- será en cambio una arcadia de la cotidianidad preurbana, donde lo abyecto se convierte en amable galería de personajes seductores, cabales o picarescos, y donde incluso el otro popular —el del pasado- será literariamente redimido.

La dimensión del cambio discursivo ocurrido dentro del género acaso pueda calibrarse mejor si se compara este texto, por ejemplo, con el antes citado de Luis Delgado Correa, "Un día festivo en Caracas", pues de algún modo se trata de la construcción —en última instancia-ficcional del mismo espacio físico y humano. La nostalgia escritural no supone en Bolet Peraza ni los aspavientos ni la convocatoria de vuelta a los valores tradicionalmente conservadores - la religión, las glorias patrias-, pues el lugar de la enunciación supone no sólo la asunción de la modernidad del "progreso", sino una ambigua reconciliación en el pasado, en la memoria - con los mortales del "atraso", con los que los ciudadanos lectores del presente pueden también identificarse. Quizás pueda leerse aquí la misma respuesta desencantada ante la modernización que algunos críticos quieren leer en los tradicionistas (Núñez xi; Oviedo xxvi-ii); pero acaso sea más productivo equiparar el trabajo de Bolet Peraza a la voluntad de construir otro tipo de "mestizaje literario", entre el pasado colonial y el presente republicano, que Oviedo ve en Ricardo Palma (Oviedo xxx); o asignar a la intencionalidad de este costumbrista venezolano un aliento similar al del tradicionista peruano: la expresión del "ánimo regresivo de la pequeña burguesía peruana 
que contemplaba con nostalgia su propio pasado (...) y para la que 'todo tiempo pasado fue mejor"' (Oviedo xxxvi-ii). No obstante, definir en términos exclusivamente regresivos, desencantados o nostálgicos este tipo de propuesta, supondría menospreciar la otra cara afirmativa - del discurso, legible tanto en el carácter en última instancia prohijador de la modernización - la voluntad de escribir un "legado" para el presente y la posteridadcomo en la nula oposición que su arribo genera.

En el otro extremo del espectro se ubicará, como se dijo, la crítica a ciertas instituciones y prácticas de la naciente sociedad burguesa del momento - el mundo de las apariencias y los compromisos sociales, el autoritarismo en el sistema educativo-pero básicamente en tanto crítica que, a veces desde la irreverencia, más que proponer una vuelta al pasado, se regodea en el cuestionamiento de prácticas y valores sociales institucionalizados; función que desde esos años y posteriormente será asumida con mayor vigor por el cuento o la novela (en José Rafael Pocaterra, por ejemplo). En este sentido, un ejemplo curioso en el que se funde una perspectiva nostálgica con una cierta irreverencia crítica se encuentra en "Los muchachos de Caracas", de Eugenio Méndez y Mendoza. En este texto, el autor, ante lo macilento y soso de la juventud del presente, reivindica a los jóvenes del pasado, vistos ahora como promotores del desastre, de "aquellas magnas manifestaciones colectivas de otros tiempos que conmovían a un barrio entero y hacían sudar la gota gorda a la policía" (Antología 350). Los bárbaros del primer costumbrismo serán ahora "heroicos adalides", proscritos novicios del irrespeto a la Iglesia, la Ley, el Orden y las Instituciones, carnavalescos personajes llenos de vida muertos para el presente, que cronológicamente bien podrían corresponder a los bárbaros caraqueños de la época del viajero de Cagigal. El texto de Méndez y Mendoza funcionaría, pues, como encrucijada en la que se traba la nostalgia pero en dependencia de la crítica - ahora sí- desencantada del presente modernizado y de los valores burgueses y la limitada reivindicación de la barbarie, la invitación al desafuero, restringida por los límites de la memoria literaria.

Pero acaso mayor resonancia tuvo por esa época la atención prestada al gran protagonista de estos otros textos costumbristas de finales del XIX: el ciudadano. Por esta vía, el costumbrismo se unirá, de alguna manera, a la lectura de los manuales de urbanidad (González). El moldeamiento conductual y moral del ciudadano en el costumbrismo, se expresaría principalmente a través del registro de personajes-individuos susceptibles de articularse a la idea de tipos representativos del mal y buen ciudadano. En este sentido, la idea de "Semblanzas de mi tiempo", título que agrupa a varios textos costumbristas de uno de los más reconocidos costumbristas de su tiempo, Francisco de Sales Pérez, no deja de ser sintomática. Así, "El baladrón" —el arrogante de diversas jerarquías y clases que abusa de su autoridad y su poder-, del mismo Sales Pérez, es un inmejorable ejemplo de modelo negativo de ciudadano. Y "Los lunes de don Rufino", de F. Tosta García, que hace el retrato de un solidario y generoso casero, o "Hipólito" de Sales Pérez, que lo hace de un gentil y disciplinado policía, sirven de modelos del buen ciudadano. Curiosamente $-\mathrm{y}$ no en vano- en ambos casos se trata de la dulcificación de figuras socialmente antipáticas pero indispensables para el sostenimiento de aparatos sociales de la sociedad burguesa moderna.

Más sofisticado es el ejemplo modélico de "El boga del río Zulia" de José María Rivas, pues se trata ahora de un personaje popular que, vinculado a la actividad comercial, enlaza en su ejercicio lo urbano y lo rural. A partir de él se construirá una de las imágenes del otro 
popular más recurrentes de la modernidad de la cultura de masas; según se vea, la más eficaz (por urbanizada o domesticada) o la más engañosa y siniestra: la del trabajador infatigable, honrado y responsable pater familias. Más que discutible legitimación, esta domesticación y "folklorización" del otro popular en tránsito a lo urbano, dada en la figura del boguero de Rivas, es caso el envés de tentativas que, como el festejo que el mismo Rivas hace del mundo del mercado marabino en "El mercado" - texto en el que se registra además con cierta sistematicidad y sin distancia el voseo, es decir, el habla "otra"-, o la conversión del granuja del pasado en simpático pícaro de la escritura en el homónimo texto ya aludido de Bolet Peraza, esbozan el gesto de un acercamiento legitimador $-\mathrm{y}$ regulador - de esos sectores que constituirían las llamadas "masas" y "muchedumbres" de las ciudades. Es el brillo y la trampa de la escritura costumbrista en los inicios de la modernización. Imágenes a un tiempo alternativas y museísticas.

\section{BiBLIOGRAFÍA}

Anderson, Benedict. Comunidades imaginadas. Reflexiones sobre el origen y la difusion del nacionalismo. México: Fondo de Cultura Económica, 1993.

Antología de costumbristas venezolanos del Siglo XIX. (6 $6^{\mathrm{a}}$ ed.). Caracas: Monte Avila, 1980.

Barrios, Alba Lía. Primer costumbrismovenezolano. Caracas: Ediciones La Casa de Bello, 1994.

Bolet Peraza, Nicanor. "Mi primer artículo". Nicanor Bolet Peraza 4. Caracas: Colección Clásicos Venezolanos de la Academia de la Lengua, 1963. 8-13.

Bueno, Salvador. "Prólogo" a Costumbristas cubanos del siglo XIX, 115. Caracas: Biblioteca Ayacucho, 1985.

Cornejo Polar, Antonio. La formación de la tradición literaria en el Perú. Lima: Centro de Estudios y Publicaciones, 1989.

"La literatura hispanoamericana del siglo XIX: continuidad y ruptura". Esplendores y miserias del siglo XIX. Cultura y sociedad en América Latina. Beatriz González, Javier Lasarte, G. Montaldo, M. J. Daroqui, comps. Caracas: Monte Avila, 1995. 1123.

Díaz Seijas, Pedro. "Hacia un concepto del costumbrismo en Venezuela". Antología de costumbristas venezolanos del siglo XIX. 1980. 423-435.

González, Beatriz. "Modernización y disciplinamiento. La formación del ciudadano: del espacio público y privado". Esplendores y miserias del siglo XIX. 1995. 431-455.

Kirkpatrick, Susan. "The Ideology of Costumbrismo". Ideologies and Literature, II/7 (1978): 28-44.

Núñez, Estuardo. "Prólogo" a Tradiciones hispanoamericanas, 67. Caracas: Biblioteca Ayacucho, 1979.

Oviedo, José Miguel. "Palma entre ayer y hoy". Prólogo a Ricardo Palma. Cien tradiciones peruanas, 7 ( $2^{\mathrm{a}} \mathrm{ed}$.). Caracas: Biblioteca Ayacucho, 1985.

Picón Salas, Mariano. "Prólogo" a Antología de costumbristas venezolanos del siglo XIX. (1980) 5-9. 
Sarlo, Beatriz y Carlos Altamirano. "Prólogo" a Esteban Echeverría. Obras escogidas, 170. Caracas: Biblioteca Ayacucho, 1991.

Semprum, Jesús. "Julio Garmendia". Crítica Literaria. Maracaibo: Fondo Editorial de Autores y Temas Zulianos, 1981. 